\title{
George Godber GCB
}

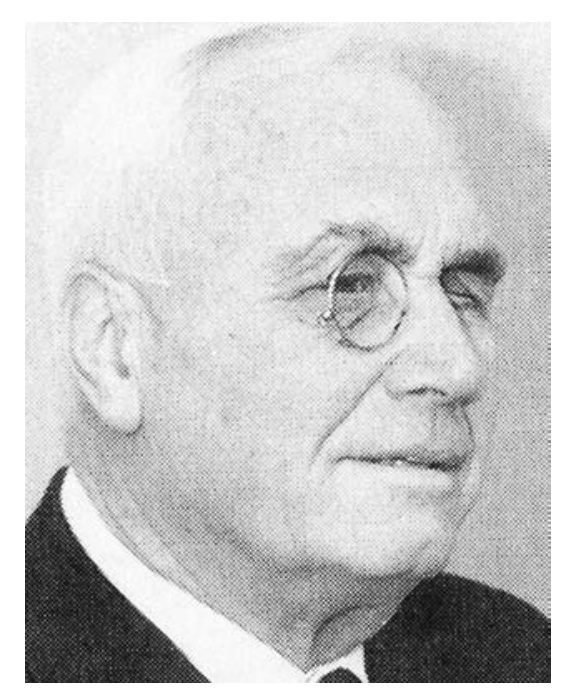

Sir George Godber GCB, who died on 7 February this year, was Chief Medical Officer at the Department of Health and Social Security from 1960 until 1973.

His appointment was no surprise. Two predecessors in the same post had marked him as an exceptionally promising, obvious candidate.

$\mathrm{He}$ made many outstanding contributions to health and medical care - by securing the even distribution of specialists across the whole country; by the development of primary care teams, of health centres and of postgraduate education. He gave essential support to the campaign against cigarette smoking and to making the contraceptive pill available on prescription. He was responsible for the Confidential Enquiry into Maternal Deaths (1952).

$\mathrm{He}$ was made an Honorary Fellow of this College in 1974, having originally joined as an associate member in 1959, (an unique gesture by someone working in the public health service).

In 1965 George Godber was involved in the set up of the Family Doctor Charter and the new contract was introduced the following year. The contract represented '... a genuine liberation from an obsolete and inegalitarian system of renumeration."

I was present in 1969 when, as CMO, he declared in a public speech his opinion that the formation of the College had been the most important single development in medicine in this country since the start of the NHS. It always received his unfailing support. In a letter to the Honorary Secretary of Council, he wrote: 'I think the achievements of the last 17 years are without parallel in medical organisations in this country'.

In the 1970s and 1980s he chaired a number of committees for the RCGP, including the Scientific Foundation Board. Giving the William Pickles lecture just after the centenary of Pickles' own birth, he referred to it as 'the greatest honour I have received since qualifying 52 years ago.' His lecture shows that he remained firmly committed to the principles on which the NHS had been founded; for instance, while extolling Pickles' own successes he stated that: 'the justification for this College is not individual achievement, but the collective effort now required from family doctors as a group.' He finished with the hope 'to be around as an observer for some time yet." ${ }^{\prime 2}$ The date was 1985.

The son of a Bedfordshire marketgardener, he lost the use of one eye through a childhood injury. This limited his choice of career within medicine. But it did not deter him from driving his car on the roads familiar to him in Cambridge, where he went to live on retirement in 1973, nor from playing golf every week. It was there that he developed a new occupation as a lecturer in the University of the Third Age, where his chosen subjects were Egyptology and Mediaeval wall and glass paintings.

Sir George was 101 when he died in residential care, 10 years after the loss of his wife, Norma, whom he had first met when she too had been a medical student at the London Hospital. Earlier in life they had suffered the loss of four of their seven children from an inborn metabolic error. Their daughter had been a nurse, one son a psycho-geriatrician, one a civil servant in the Department of Health.

I treasure the letters, always handwritten, from a man who achieved so much of importance, yet still had time to write to his very many friends. In one of them he wrote 'the real key to the future is in making our generalist/specialist combination an effective and equal partnership', an aim which, throughout my career I have tried to share and promote.

\section{John Horder}

\section{REFERENCE}

1. Louden I, Horder J, Webster C (eds). General practice under the National Health Service 1948-1997. Oxford: Clarendon Press, 1998.

2. Godber G. Change and continuity. William Pickles Lecture. J R Coll Gen Pract 1985; 35: 320-325.

DOI: 10.3399/bjgp09X420446 